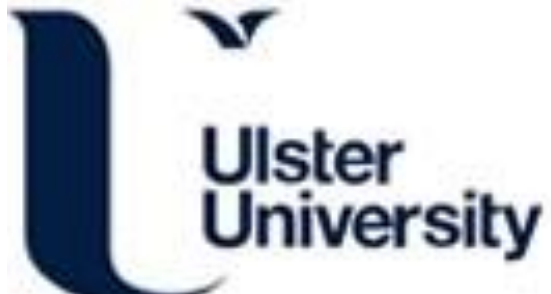

Total Phenols, Antioxidant Capacity and Antibacterial Activity of Manuka Honey Chemical Constituents

Kirkpatrick, G., Nigam, P., \& Owusu-Apenten, R. K. (2017). Total Phenols, Antioxidant Capacity and Antibacterial Activity of Manuka Honey Chemical Constituents. Journal of Advances in Biology and Biotechnology, 15(4), 1-7. https://doi.org/10.9734/JABB/2017/37242

Link to publication record in Ulster University Research Portal

Published in:

Journal of Advances in Biology and Biotechnology

Publication Status:

Published (in print/issue): 06/11/2017

DOI:

10.9734/JABB/2017/37242

Document Version

Author Accepted version

\section{General rights}

Copyright for the publications made accessible via Ulster University's Research Portal is retained by the author(s) and / or other copyright owners and it is a condition of accessing these publications that users recognise and abide by the legal requirements associated with these rights.

\section{Take down policy}

The Research Portal is Ulster University's institutional repository that provides access to Ulster's research outputs. Every effort has been made to ensure that content in the Research Portal does not infringe any person's rights, or applicable UK laws. If you discover content in the Research Portal that you believe breaches copyright or violates any law, please contact pure-support@ulster.ac.uk. 


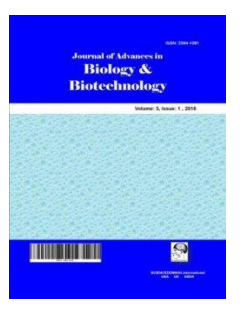

\title{
Total Phenols, Antioxidant Capacity and Antibacterial Activity of Manuka Honey Chemical Constituents
}

\author{
Graeme Kirkpatrick ${ }^{1}$, Poonam S. Nigam ${ }^{1}$ and Richard Owusu-Apenten ${ }^{{ }^{*}}$ \\ ${ }^{1}$ School of Biomedical Sciences, University of UIster, Coleraine, BT52 1SA, UK.
}

Authors' contributions

This work was carried out in collaboration between all authors. Authors ROA and PSN designed the study and wrote the protocol. Author GK performed the study, managed the literature searches, performed the statistical analysis, and wrote the first draft of the manuscript in partial fulfilment of his MSc degree. All authors read and approved the final manuscript.

Article Information

DOI: $10.9734 / J A B B / 2017 / 37242$

Editor(s):

(1)

(2)

Reviewers:

\section{ABSTRACT}

Aims: To compare the total phenol content, antioxidant capacity and antibacterial activity of methyl syringate (MSY), methylglyoxal (MGO) and phenyllactic acid (PLA) as major components from Manuka honey

Study Design: In-vitro study.

Place and Duration of Study: Nutrition Innovation Centre for Food and Health (NICHE), School of Biomedical Sciences, University of Ulster, Coleraine Campus, between June 2016 and September 2017.

Methodology: Total phenols content (TPC) was determined using the Folin-Ciocalteu assay. Antioxidant capacity was evaluated as 2,2'-Azino-bis(3-ethylbenzthiazoline-6-sulfonic acid (ABTS) radical quenching activity or iron (III) reducing antioxidant capacity (IRAC). Antibacterial activity was measured using the disc diffusion assay with, E.coli, Bacillus subtilis or Staphylococcus aureus. Results: The TPC for MSY was $60.8 \%$ gallic acid equivalents (GAE) and significantly higher than 
1.6-3.2\% GAE observed for MGO or PLA. The antioxidant capacity for MSY (128\% to $270 \%$ trolox equivalents (TE)) was significantly higher compared with $-6 \%$ to $4.4 \%$ TE for MGO or PLA. A disc diffusion assay for MGO and PLA showed antibacterial power but MSY had no antibacterial activity. Conclusion: Methylglyoxal and PLA from Manuka honey showed antibacterial activity but no detectable antioxidant and total phenol character. Methyl syringate, which shows high antioxidant capacity and TPC, had no detectable antibacterial activity. Total phenols content and antioxidant power of Manuka honey is unlikely to be related to its antibacterial activity.

Keywords: Manuka honey; honey components; antibacterial; antioxidant; methylglyoxal; methyl syringate; phenyllactic acid.

\section{INTRODUCTION}

Honey has a complex chemical makeup, which gives it unique biological properties varying from wound healing, antimicrobial power to anticancer effects [1-3]. Honeys vary greatly in composition, influenced by geographic location, floral source, storage conditions and other factors [2]. Manuka honey is characterized by a high non-peroxide antibacterial activity that remains after dilution and pre-treatment with catalase [3]. Manuka honey also exhibits high antioxidant capacity and high levels of polyphenols $[4,5,6]$. The total phenol content and methylglyoxal (MGO) content increase with the Unique Manuka Factor $(\mathrm{UMF})^{\mathrm{TM}}$ rating $[4,5]$; $(\mathrm{UMF})^{\mathrm{TM}}$ is a commercial rating that indicates an equivalent concentration of phenol solution which gives the same antibacterial activity as honey [4]. Specific chemical markers for Manuka honey quality include MGO [4,5], methyl syringate (MSY) [7] and syringic acid glycoside or leptosin [8].

Antibiotic resistance is becoming a growing problem. Currently, bacterial resistance towards honey has not been observed. The antibacterial activity of Manuka honey correlates with the total antioxidant capacity and UMF rating [1-3]. Resent research suggests that MGO is a major antibacterial compound in Manuka honey $[9,10,11,12]$. However, the contributions of MSY and phenyllactic acid (PLA) to antibacterial activity of Manuka honey is uncertain [7]. Meanwhile, PLA was identified from lactic acid bacteria fermentation as a broad-spectrum antibacterial agent [13]. UMF-rated honey possess high levels of MGO and polyphenols, but the relations of these indices to antibacterial activity is not wholly understood. The aims of this study were to, compare total phenol content, antioxidant capacity and antibacterial power for MSY, MGO and PLA from Manuka honey (Fig. 1). The results are discussed in terms the possible basis for honey antibacterial activity.<smiles>COc1cc(OC)c(O)c(OCCCCCO)c1</smiles>

Gallic acid(170.12) Methyl syringate (212.2)<smiles>O=C(O)C(O)Cc1ccccc1</smiles>

Phenyllactic acid (166.7)<smiles>COc1cc(/C=C/C(=O)O)ccc1O</smiles><smiles>CC(=O)C=O</smiles>

Methylglyoxal (72.06)

Transferulic acid (194.18)<smiles>Cc1c(C)c2c(c(C)c1O)OC(C)(C(=O)O)CC2</smiles>

Trolox (250.2)

Fig. 1. Chemical structures some organic compounds in this report

Formula weights are shown in parenthesis

\section{MATERIALS AND METHODS}

\subsection{Preparation of Samples}

Manuka honey $(\mathrm{MH})$ rated UMF18+ was from Comvita Ltd. (UK). Methyl syringate, MGO, PLA, TFA $(1000 \mu \mathrm{M})$ were dissolved in $20 \%$ methanol: water solvent as was trolox and gallic acid used as calibration standards. The reference antioxidants were diluted to $500 \mu \mathrm{M}, 250 \mu \mathrm{M}$, $125 \mu \mathrm{M}$, and $62.5 \mu \mathrm{M}$ before use.

\subsection{Folin-Ciocalteu Total Phenol Assay}

The Folin-Ciocalteu method [14] was used to determine the apparent TPC for honey MGO, PLA and MSY. This assay, which is dependent on tungsten-molybdate complexes is sensitive to 
phenols and reducing agents. Gallic acid (50 $\mu$; 0-1 $\mathrm{mM}$ ) was added to microcentrifuge tubes, with $100 \mu \mathrm{l}$ of Folin-Ciocalteu and $850 \mu \mathrm{l}$ sodium carbonate. The microcentrifuge tubes were vortexed briefly and incubated at $37^{\circ} \mathrm{C}$ for 20 minutes. Thereafter, $200 \mu$ of the sample was transferred to a 96-well microplate (x4 $200 \mu \mathrm{l}$ per sample), and absorbance was measured at 760 $\mathrm{nm}$ (A760) using a microplate reader (VersaMax model reader; Molecular devices, Sunnydale, California, USA).

\subsection{Iron (III) Reducing Antioxidant Capacity (IRAC) Assay}

The IRAC method is a modification of the Ferric Reducing Ability of Plasma (FRAP) assay [15], adapted for 96-well microplate format [16], and adjusted to function at $\mathrm{pH} 7$ [17]. The IRAC reagent comprised $20 \mathrm{mg}$ of ferrozine, dissolved with $18 \mathrm{ml}$ of Tris buffer ( $\mathrm{pH} 7.0)$ and, mixed with $8 \mathrm{mg}$ of ferric (III) ammonium sulphate $(8 \mathrm{mg})$ dissolved with $2 \mathrm{ml}$ of deionized water. The microplate IRAC analyses involved adding $20 \mu$ of sample (MSY, PLA, TFA or MGO at $0-1 \mathrm{mM}$ ) or reference antioxidant (trolox) to a flat-bottomed 96 -well microplate followed by 280 $\mu \mathrm{l}$ of the IRAC solution. The reaction mixtures were incubated at $37^{\circ} \mathrm{C}$ for 30 minutes, and absorbance readings were recorded at $562 \mathrm{~nm}$ (A562) using a microplate reader (VersaMax model; Molecular devices, Sunnydale, California, USA). Each study was repeated on two or more occasions, with triplicate readings per experimental point. IRAC results are cited as, trolox equivalent antioxidant capacity (TEAC).

\subsection{ABTS Assay for Antioxidant Capacity}

The ABTS assay was performed as described previously [18] with adjustments made for 96-well microplate application. The microplate analyses were carried out by adding $20 \mu$ of sample (MSY, PLA, TFA or MGO at $1 \mathrm{mM}$ ) or reference antioxidant (trolox) at concentrations stated to a flat-bottom 96-well microplate followed by $280 \mu \mathrm{l}$ of the ABTS working solution. The reaction mixtures were then agitated briefly before being incubated at $37^{\circ} \mathrm{C}$ for in the dark 30 minutes, and absorbance readings were recorded at $734 \mathrm{~nm}$ (A734) using a microplate reader as above. The ABTS results are expressed as TEAC values.

\subsection{Antimicrobial Determination}

\subsubsection{Bacterial strains and growth conditions}

Bacterial strains were from the Centre of Molecular Biology (CMB), Ulster University. Staphylococcus aureus (S. aureus), Escherichia coli (E. coli) and Bacillus subtilis (B. subtilis) were routinely cultivated in either nutrient agar or broth medium at $37^{\circ} \mathrm{C}$ with shaking.

\subsubsection{Determination of antimicrobial activity - disk diffusion}

Disc diffusion antibacterial assays were performed as described previously [19]. A 24hour bacteria liquid culture $(200 \mu \mathrm{l})$ was spread evenly over nutrient agar plates using a sterile spreader and allowed to dry. Six blank paper disks were added to each agar plate and $20 \mu$ of each test solution (and controls) were added. To ensure that paper discs were loaded with comparable amounts of tests compounds it was assumed that the maximum occurrence MSY, PLA or MGO from Manuka honey would not exceed 1500 ppm (1.5 mg/ml) [4], corresponding to PLA (9 mM), MSY (7 mM) and MGO (20 mM). Manuka honey (UMF 18+) tested as $25 \% \mathrm{w} / \mathrm{v}$ solution $(20 \mu \mathrm{l})$ loads $\sim 7 \mu \mathrm{g}$ per disc for each component. Therefore, we prepared MGO $(2 \mathrm{mg} / \mathrm{ml})$, PLA $(2 \mathrm{mg} / \mathrm{ml})$ or MSY $(1.1 \mathrm{mg} / \mathrm{ml})$ using $20 \%$ sterile methanol: water solvent and loaded $20 \mu \mathrm{l}(30-40 \mu \mathrm{g})$ per paper disc. Tests also involved $20 \%$ methanol: water solvent as negative control. Pen-Strep (5000 U/ml penicillin \& $5000 \mu \mathrm{g} / \mathrm{ml}$ streptomycin; Gibco ThermoFisher Scientific) was used as a positive control for antibacterial assays ( $16 \mu \mathrm{g}$ per paper disc). Agar plates were incubated at $37^{\circ} \mathrm{C}$ for 24 hours and the diameter of the zones of inhibition was measured. We used a laminar flow cabinet to ensure sterility. Results are an average of duplicate observations.

\subsection{Statistical Analysis}

Antioxidant assays were conducted in triplicates on two separate occasions. Microplate data were exported to excel for graphing and calculations. Calibration graphs were produced by plotting absorbances minus reagent blanks on the y-axis, against the concentration of the specific standard; Gallic acid or trolox (in the assay) on the x-axis. Molar absorptivity was determined by taking the gradient of the linear regression trend line where $y=m x$. The 
regression coefficient $\left(R^{2}\right)$ was maximized by deletion of high points on the graph.

The disk diffusion assay for antibacterial activity was conducted in duplicate on two different occasions. The averages of the results are displayed in the figures and tables shown with errors given as standard deviation (SD) or standard error of the mean (SEM) where specified. To test for significance we used one-way Anova (IBM SPSS (V24). An alpha value of $P<0.05$ was used to determine significance.

\section{RESULTS AND DISCUSSION}

\subsection{Calibration Characteristics of Folin, IRAC and ABTS Assays}

Calibration graphs for antioxidant assays were linear $(R 2>0.98)$ with an upper limit of 1.25-25 $\mu \mathrm{M}$ corresponding to a prepared concentrations of $\leq 0.5 \mathrm{mM}$. The equations of the line in Table 1 were employed for determining the total phenol (Folin assay) or antioxidant capacity (ABTS \& IRAC) for PLA, MSY and MGO.

\subsection{Total Phenols Content or Character}

Manuka honey possesses high total phenol content, high antioxidant capacity, and high concentrations of MGO which increase with the UMF rating $[2,3,4,5]$. The pure constituents (MSY, MGO and PLA) investigated in this paper occur in high concentrations in Manuka honey [4, $6,7]$ with two (MGO and MSY) proposed as makers of quality $[7,8]$. Stephens and co- workers analyzed phenolic acids from 8 samples of Manuka honey and found an average, maximum and minimum PLA level of $1513 \mathrm{mg} / \mathrm{kg}$, $1920 \mathrm{mg} / \mathrm{kg}$ or $980 \mathrm{mg} / \mathrm{kg}$, respectively [4]. Syringic acid and MSY combined were the second major components with an average, maximum and minimum levels of $145 \mathrm{mg} / \mathrm{kg}, 429$ $\mathrm{mg} / \mathrm{kg}$, and $5.2 \mathrm{mg} / \mathrm{kg}$. In a separate analysis, the same samples of Manuka honey contained an average, maximum and minimum MGO value of, $1085 \mathrm{mg} / \mathrm{kg}, 1541 \mathrm{mg} / \mathrm{kg}$, or $651 \mathrm{mg} / \mathrm{kg}$ honey [4]. Another study of honey phenolics identified a major component as 2-hydroxy-3-phenylpropionate (synonym, (R)-3-phenyllactate PubChem ID 5461132) with an average, minimum and maximum level of, $1769 \mathrm{mg} / \mathrm{kg}$, $733 \mathrm{mg} / \mathrm{kg}$ and $4474 \mathrm{mg} / \mathrm{kg}$ [6]. In this study, we included trans-ferulic acid (TFA) because its chemical structure bears some similarity to PLA [20] except TFA has an $\mathrm{OH}$ group on its benzene ring making it a phenolic compound (Fig. 1).

The total phenol responses for different organic constituents from Manuka honey converted to $\mathrm{mg}-\mathrm{GAE} / 100 \mathrm{~g}$ is shown in Fig. 2. To check the validity of this analysis, the total phenol character for gallic acid was determined to be 97684 ( \pm 3254) $\mathrm{mg} / 100 \mathrm{~g}$, which is $\sim 98 \%$ GAE. The total phenol response for MSY was $60.8 \%$ GAE whilst TFA yielded $63.6 \%$ GAE (Fig. 2). The results for MGO and PLA indicated an apparent total phenol response of $3.2 \%$ GAE and $1.6 \%$ GAE, respectively. The high GAE value for MSY and TFA should be as expected as these are phenolic compounds with an $\mathrm{OH}$ group on their benzene ring (Fig. 1).

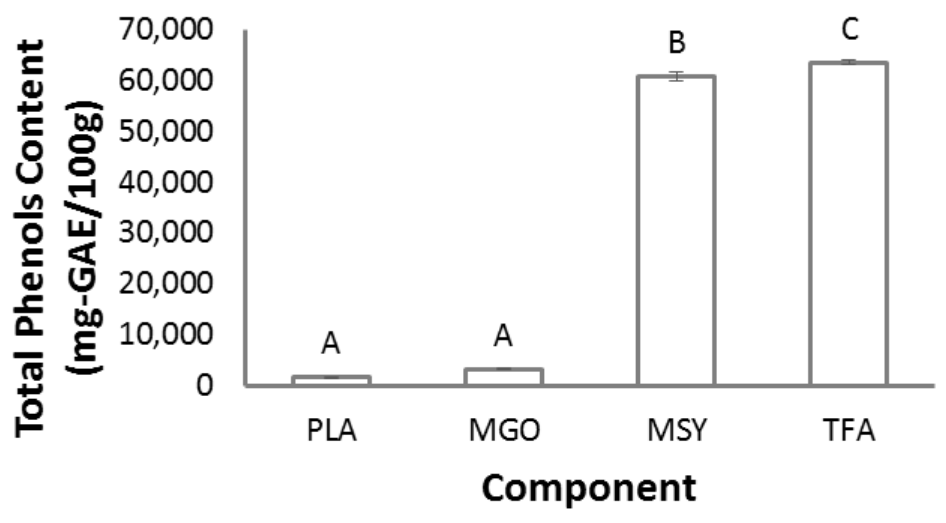

Fig. 2. Total phenols character for some components from honey

Phenyllactic acid (PLA), methylglyoxal (MGO), methyl syringate (MSY), Trans-ferulic acid (TFA) is a phenolic comparator for PLA. Lettered data labels show significantly different groups $(P<0.05)$ 
Table 1. Calibration parameters for folin and antioxidant capacity assays

\begin{tabular}{llll}
\hline Assay & Reference standard & Equation & $\mathbf{R}^{\mathbf{2}}$ \\
\hline Folin & Gallic acid & $\Delta \mathrm{A} 760=13447 \mathrm{x}$ & 0.9961 \\
ABTS & Trolox & $\Delta \mathrm{A} 734=17603 \mathrm{x}$ & 0.9962 \\
IRAC & Trolox & $\Delta$ A562 $=39968 \mathrm{x}$ & 0.9805 \\
\hline Calibration data for Folin-Ciocalteu, ABTS or Iron (III) Reducing & Antioxidant Capacity (IRAC) assay respectively.
\end{tabular}

\subsection{Total Antioxidant Capacity}

Analysis using the ABTS assay showed that MSY had high radical quenching capacity, corresponding to $270 \%$ TEAC or $27000 \mathrm{mg}$ TE per $100 \mathrm{~g}$ of MSY. TFA had a radical quenching capacity of $170 \%$ TEAC. As a check on the validity of this approach, ABTS analysis for trolox produced a TEAC value of $114370( \pm 6511)$ $\mathrm{mg} / 100 \mathrm{~g}$ in other words $114 \pm 6.5 \% \mathrm{TE}$. However, the radical quenching capacity was $4.2 \%$ TE for MGO and $1.7 \%$ TE for PLA and the values were not significantly different from each other (Fig. 2). In the preceding analysis, the results of ABTS assay were presented as TEAC units [18] and not as $\%$ inhibitory concentrations. Using values for TEAC allows a comparison of antioxidant (ABTS \& IRAC) assay results (see below).

According to the IRAC assay, pure MSY showed antioxidant power equal to $128 \%$ TE, whilst TFA had antioxidant capacity equal to $89 \%$ TE. By comparison, Trolox used a reference for the IRAC assay showed antioxidant power of 107016 $( \pm 5242) \mathrm{mg} \mathrm{TE} / 100 \mathrm{~g}$ or $107 \pm 5.2 \%$ TE. When MGO and PLA were analyzed by the IRAC assay the antioxidant capacity was minus $6.6 \% \mathrm{TE}$, which is effectively, zero (Fig. 3 ).
The antioxidant capacity for MSY, TFA, PLA, and MGO are broadly consistent with their chemical structures (Fig. 1). The number of $\mathrm{OH}(\mathrm{O}-)$ groups attached to benzene ring is a determinant for antioxidant power for phenols. The present results suggest that MSY is a major contributor to the antioxidant capacity for Manuka honey. By contrast, PLA and MGO, which occur in similar or greater quantities [4], do not contribute enormously to the antioxidant capacity for Manuka honey.

\subsection{Antimicrobial Activity}

\subsubsection{Disk Diffusion}

It is thought that MGO accounts for a large part of the non-peroxide antibacterial activity from Manuka honey $[9,10,11,12]$ but the data for MSY is conflicting $[1,7]$. PLA is difficult to observe by HPLC analysis and is not characterized for antibacterial activity in Manuka honey [4]. The disc diffusion assay (Table 2) showed that MGO, PLA and unfractionated Manuka honey possess antibacterial activity. Apparently, MSY had no antibacterial activity against, E. coli, S. aureus, or $B$. subtilis strains, at the concentration tested.

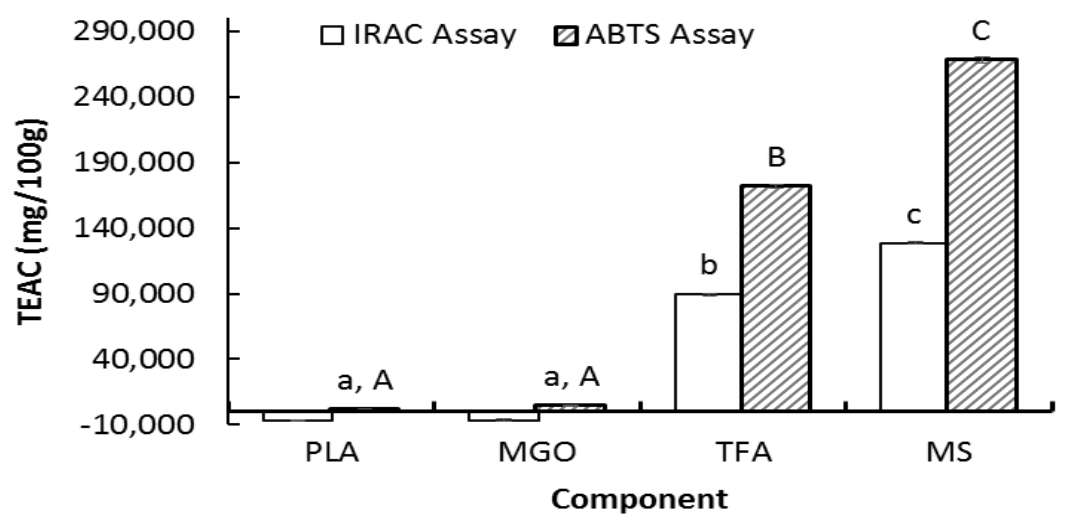

Fig. 3. Antioxidant capacity for honey compounds using the ABTS and IRAC assays $P L A=$ phenyllactic acid, MGO = methylglyoxal, TFA = tetra ferulic acid. Results are expressed as Trolox equivalent antioxidant capacity (TEAC). Within each assay, bars with different labels show significantly different groups $(P<0.05)$ 
Table 2. Zone of inhibition from disc diffusion assay for MH components*

\begin{tabular}{lllllll}
\hline & MGO & MSY & PLA & MH & Pen-Strep & Meth \\
\hline E. coli & $30.5^{\mathrm{D}} \pm 0.5$ & $6.5^{\mathrm{A}} \pm 0$ & $12.5^{\mathrm{B}} \pm 0.5$ & $23^{\mathrm{C}} \pm 0$ & $32^{\mathrm{D}} \pm 0$ & $6.5^{\mathrm{A}} \pm 0$ \\
S. aureus & $30^{\mathrm{D}} \pm 0$ & $6.5^{\mathrm{A}} \pm 0$ & $13^{\mathrm{B}} \pm 0$ & $23^{\mathrm{C}} \pm 1$ & $29.5^{\mathrm{D}} \pm 0.5$ & $6.5^{\mathrm{A}^{2} \pm 0}$ \\
B. subtilis & $20^{\mathrm{C}} \pm 1$ & $6.5^{\mathrm{A}} \pm 0$ & $13^{\mathrm{B}} \pm 0$ & $17.5^{\mathrm{C}} \pm 0.5$ & $21.5^{\mathrm{C}} \pm 1.5$ & $6.5^{\mathrm{A} \pm 0}$ \\
\hline
\end{tabular}

${ }^{*}$ Average diameter of the Zones of Inhibition from two replicates \pm Standard error of the mean (SEM). The measurements include the size of the paper disk (6.5mm). Loadings per disc was $20 \mu \mathrm{l}$ for Methylglyoxal (MGO; $2 \mathrm{mg} / \mathrm{ml})$, methyl syringate (MSY; $1.1 \mathrm{mg} / \mathrm{ml})$, phenyllactic acid (PLA, 2mg/ml), Manuka honey (MH; 25\% w/v),

Pen-Strep ( $8 \mathrm{mg} / \mathrm{ml})$ is a positive control; and Meth=methanol: water mixture (20\% $/ \mathrm{v})$ negative control, Treatment time was 24 hours before measurement

\section{CONCLUSION}

Manuka honey components (MSY, PLA and MGO) exhibit different levels of total phenol character, antioxidant capacity and antibacterial power. Analysis using the Folin-Ciocalteau method showed that PLA and MGO had virtually no phenols character. The phenols response for MSY was $60.8 \%$ GAE consistent with the chemical structure (Fig. 1). The antioxidant capacity of MSY was high (128-270\% TEAC) whilst antioxidant capacity of MGO and PLA were virtually zero. Assays for antibacterial activity were positive for MGO and PLA but MSY had no activity. Therefore, the total phenol and antioxidant components from Manuka honey may contribute poorly to the antibacterial activity. By contrast, MGO and PLA with demonstrated antibacterial activity had low antioxidant or total phenol character.

Interestingly, MGO and polyphenol content are "competing" quality indicators for Manuka honey [4,5]. Obviously, MGO and PLA appear to be better measures for the antibacterial power for Manuka honey. In contrast, the antioxidant activity from Manuka honey is attributable to MSY and related polyphenols. It is noteworthy that high concentrations of MGO, PLA, and total polyphenols seem to co-exist for UMF-rated honey $[4,5,6,16,21]$ and so the possibility exists for synergistic or destructive interactions between these components. The current results are interesting but more research, using a wider range of bacteria pathogens and assay conditions, will be needed to yield findings that are more definitive. We are currently seeking resources and collaborative opportunities from Public, Private and Industry sources to enable additional studies on the medicinal properties of honey.

\section{COMPETING INTERESTS}

Authors have declared that no competing interests exist.

\section{REFERENCES}

1. Mandal M, Mandal S. Honey: Its medicinal property and antibacterial activity. Asian Pac J Trop Biomed. 2011;1(2):154-160.

2. Carter D, Blair S, Cokcetin N, Bouzo D, Brooks $\mathrm{P}$, Schothauer R, et al. Therapeutic Manuka honey: No longer so alternative. Front Microbiol. 2016;7(1).

3. Kwakman P, Zaat S. Antibacterial components of honey. IUBMB Life. 2011;64(1):48-55.

4. Stephens J, Schlothauer R, Morris B, Yang D, Fearnley L, Greenwood D, et al. Phenolic compounds and methylglyoxal in some New Zealand Manuka and Kanuka honeys. Food Chem. 2010;120(1):78-86.

5. Oelschlaegel $S$, Gruner $M$, Wang $P$, Boettcher A, Koelling-Speer I, Speer K. Classification and characterization of Manuka honeys based on phenolic compounds and methylglyoxal. J Agric Food Chem. 2012;60(29):7229-7237.

6. Tan ST, Holland PT, Wilkins AL, Molan PC. Extractives from New Zealand honeys. 1. White clover, Manuka and Kanuka unifloral honeys. J Agric Food Chem. 1988;36(3): 453-60.

7. Weston RJ, Brocklebank LK, Lu Y. Identification and quantitative levels of antibacterial components of some New Zealand honeys. Food Chem. 2000;70(4): 427-35.

8. Kato $Y$, Araki $Y$, Juri M, Ishisaka A, Nitta $Y$, Niwa T, Kitamoto N, Takimoto $Y$. Competitive immunochromatographic assay for leptosperin as a plausible authentication marker of Manuka honey. Food Chem. 2016;194:362-5.

9. Adams CJ, Boult $\mathrm{CH}$, Deadman BJ, Farr JM, Grainger MN, Manley-Harris M, Snow MJ. Isolation by HPLC and characterisation of the bioactive fraction of New Zealand Manuka (Leptospermum scoparium) honey. Carbohydrate Res. 2008;343(4):651-9. 
10. Mavric E, Wittmann S, Barth G, Henle T. Identification and quantification of methylglyoxal as the dominant antibacterial constituent of Manuka (Leptospermum scoparium) honeys from New Zealand. Mol Nutr Food Res. 2008;52(4):483-9.

11. Atrott J, Henle T. Methylglyoxal in Manuka honey-correlation with antibacterial properties. Czech J Food Sci. 2009; 27(Spec.):S163-5.

12. Kwakman $\mathrm{PH}$, te Velde $\mathrm{AA}$, de Boer $\mathrm{L}$, Speijer D, Vandenbroucke-Grauls CM, Zaat SA. How honey kills bacteria. The FASEB Journal. 2010;24(7):2576-82.

13. Chaudhari SS, Gokhale DV. Phenyllactic acid: A potential antimicrobial compound in lactic acid bacteria. J Bacteriol Mycol Open Access. 2016;2(5): 00037.

DOI: 10.15406/jbmoa.2016.02.00037

14. Singleton VL, Orthofer R, LamuelaRaventos RM. Analysis of total phenols and other oxidation substrates and antioxidants by means of Folin-Ciocalteu reagent. Methods Enzymol. 1999;2(99): 152-78.

15. Benzie IF, Strain JJ. The ferric reducing ability of plasma (FRAP) as a measure of "antioxidant power": The FRAP assay. Analytical Biochem. 1996;239 (1):70-76.

16. Bolanos de la Torre AAS, Henderson T, Nigam PS, Owusu-Apenten RK. A universally calibrated microplate ferric reducing antioxidant power (FRAP) assay for foods and applications to Manuka honey. Food Chemistry. 2015;174(1):119123.

17. Wong CW, Cheung WS, Lau YY, Bolanos de la Torre AA, Owusu-Apenten R. A frap assay at $\mathrm{pH} 7$ unveils extra antioxidant activity from green, black, white and rooibos tea but not apple tea. F Nutr Reprt. 1(1).

18. Walker RB, Everette JD. Comparative reaction rates of various antioxidants with ABTS radical cation. J Agric Food Chem. 2009;57(4):1156-1161.

19. Fiebelkorn KR, Crawford SA, McElmeel $\mathrm{ML}$, Jorgensen JH. Practical disk diffusion method for detection of inducible clindamycin resistance in Staphylococcus aureus and coagulase-negative staphylococci. J Clin Microbiol. 2003; 41(10):4740-4744.

20. Mu W, Yu S, Zhu L, Zhang T, Jiang B. Recent research on 3-phenyllactic acid, a broad-spectrum antimicrobial compound. Appl. Microbiol. Biotechnol. 2012; 95(5):1155-63.

21. Kwok TH, Kirkpatrick G, Mohd Yusof HI, Portokalakis I, Nigam P, Owusu-Apenten R. Rapid colorimetric determination of methylglyoxal equivalents for Manuka Honey. J Adv Biol Biotechnol. 2016;7(1):16.

(c) 2017 Kirkpatrick et al.; This is an Open Access article distributed under the terms of the Creative Commons Attribution License (http://creativecommons.org/licenses/by/4.0), which permits unrestricted use, distribution, and reproduction in any medium, provided the original work is properly cited. http://sciencedomain.org/review-history/21762 